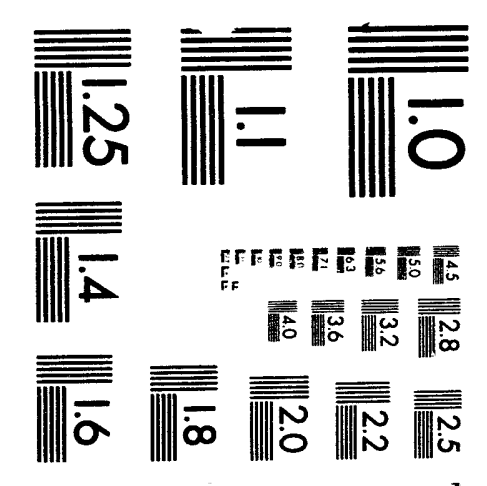



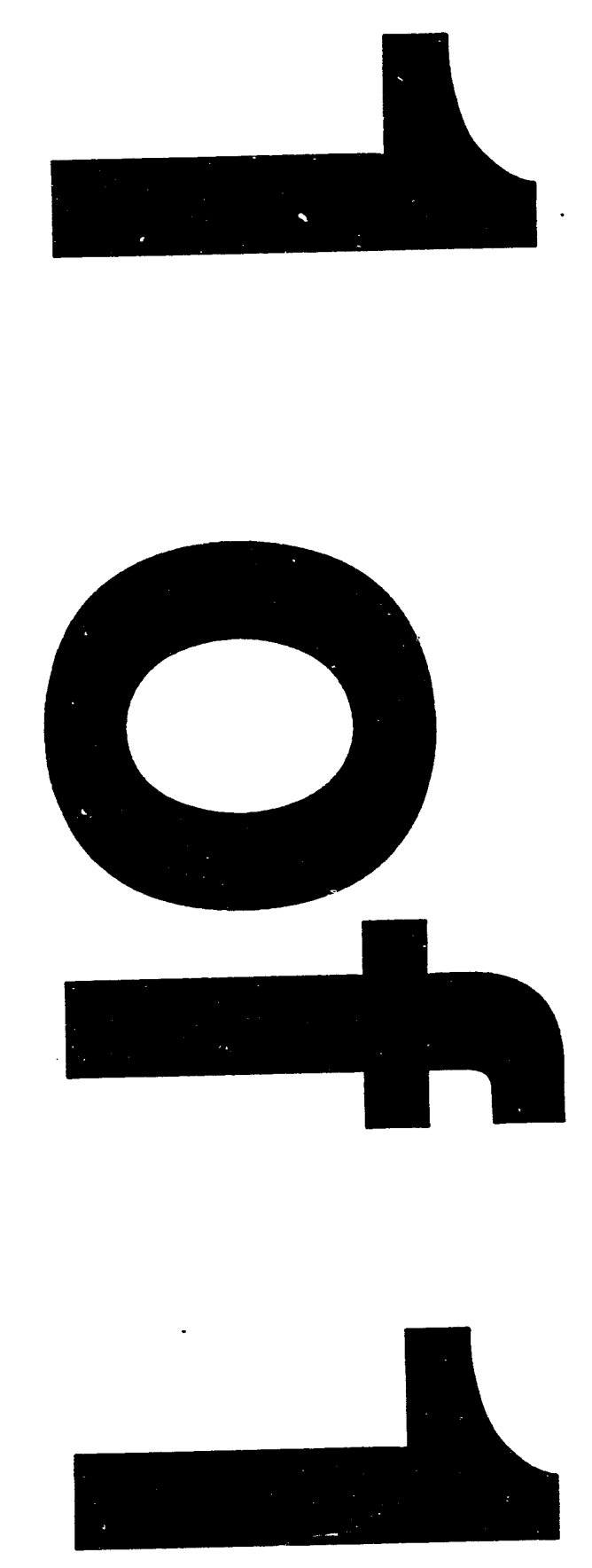

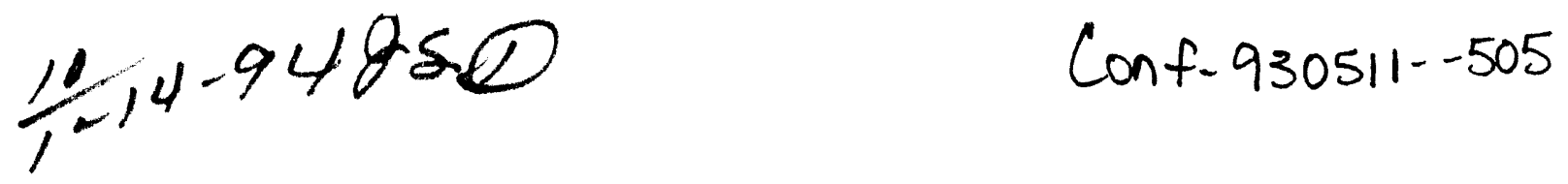

SLAC-PUB-62()2

June 1993

(A)

\title{
Induced Beam Oscillations from Quadrupole Vibrations in the SLC Linac*
}

\author{
J. T. Seeman, R. L. Holtzapple, M. C. Ross \\ Stanford Linear Accelerator Center \\ Stanford University, Stanford, California 94309 USA
}

\begin{abstract}
Linac beams in the Stanford Linear Collider (SLC) were driven into oscillation by transverse vibration of lattice quadrupoles at about $7 \mathrm{~Hz}$. These quadrupoles are centered on 12-meter support girders located early in the linac. The vibrations were caused by ground motion at the $0.06 \mu \mathrm{m}$ level which was amplified in the accelerator supports up to $5 \mu \mathrm{m}$. Seismic and support vibration measurements were Fourier analyzed and a strong correlation with beam observations was observed. Subsequent modifications of the supports have eliminated these oscillations.
\end{abstract}

\section{Introduction}

In the spring of 1992 the SLC positron beam exhibited a coherent betatron oscillation in the vertical plane apparently emanating from the damping ring or early linac. These oscillations had an amplitude of about one half the beam size at the end of the linac with a frequency of about $7 \mathrm{~Hz}$. These oscillations caused occasional accelerator trips, prompting a search for the source. Since it was a positron beam problem and not electron, the positron damping ring and ring-to-linac transport line were investigated first for power supply, kicker, or vibration problems; but none were found. This result lead to the investigation of the vertically focusing quadrupoles in the early linac. But again, no quadrupole power supply instabilities were found. Finally, the connection to vertically vibrating linac girders was made.

In the bulk of the linac the quadrupoles are placed at the end of the support girders ( $12 \mathrm{~m}$ long). The vibration for these quadrupoles mounted over the supports was measured and found to be about $0.06 \mu \mathrm{m}$, which was safely under the desired tolerance ${ }^{1,2}$. However, in the early linac additional quadrupoles were added in the center of the girders to increase the focusing and reduce the betatron functions. Thus, these quadrupoles (neccessarily stronger because of the smaller spacing) were placed where vibration amplitudes could be larger. The reason the positron vertical measurements showed the largest effects is that the quadrupoles at the center of the girders had the largest vertical offsets and these quadrupoles are vertically focusing for positrons. Horizontal oscillations should have been visible for electrons, but other upstream difficulties clouded the observations.

\section{Measured Bcam Oscillations}

The key beam evidence that the girders were vibrating came from position measurements from adjacent monitors early in the linac. Figure 1 shows beam oscillations of about $50 \mu \mathrm{m}$ on two position monitors. The two monitors are very nearly 180 degrees apart in betatron phase and should show identical but inverted oscillations. A frequency spectrum of this data shows a strong peak at a frequency of about $7 \mathrm{~Hz}$ as can be seen in Figure 2. The two data in Figure 1 are similar but definitely not just inversions of each other. Thus, the differences arose from changes between the two monitors located $24 \mathrm{~m}$ apart. For this region of the linac, the differences could only be explained by local quadrupole vibrations.

\section{Measured Girder Vibrations}

The girder which supports the lattice quadrupoles and

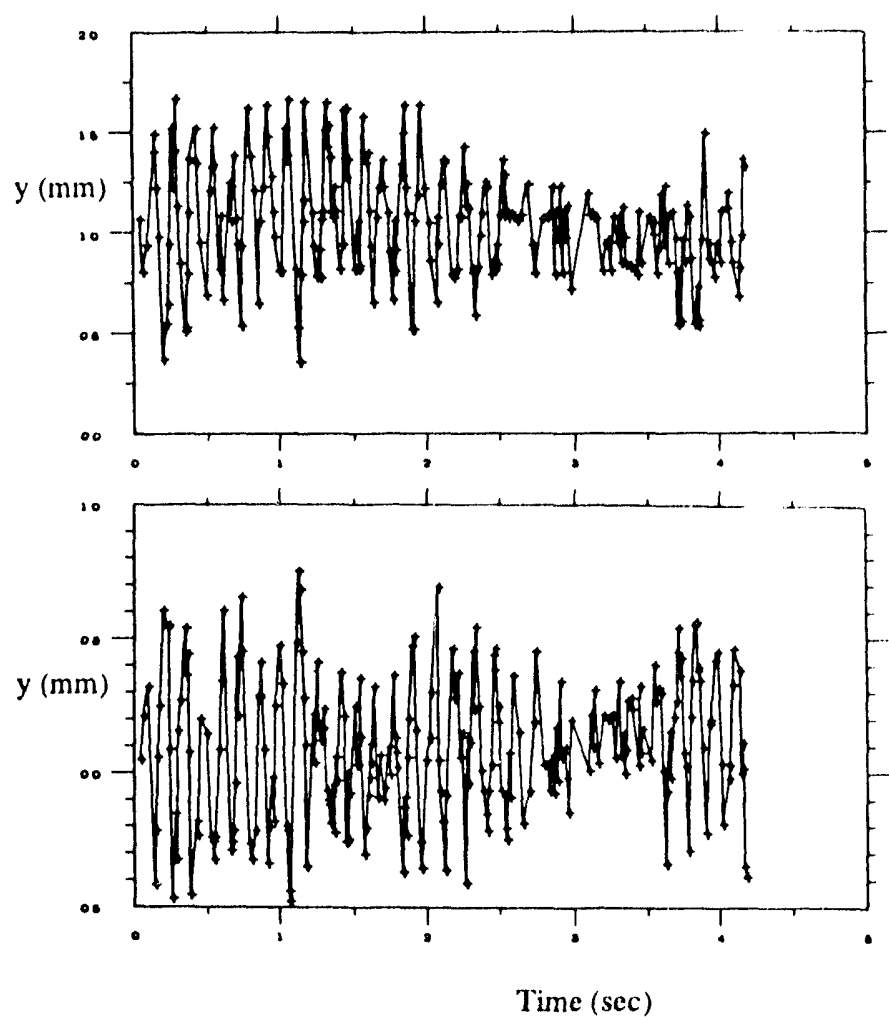

Figure 1 Observed positron vertical beam oscillations on two position monitors (L103-321, LI05-521) with time. The two monitors are $180^{\circ}$ apart in betatron phase about $120 \mathrm{~m}$ downstream of the damping rings. The energy is $2.8 \mathrm{GiV}$.

* Work supported by the Department of Energy contract DE-AC03-76SF00515. 


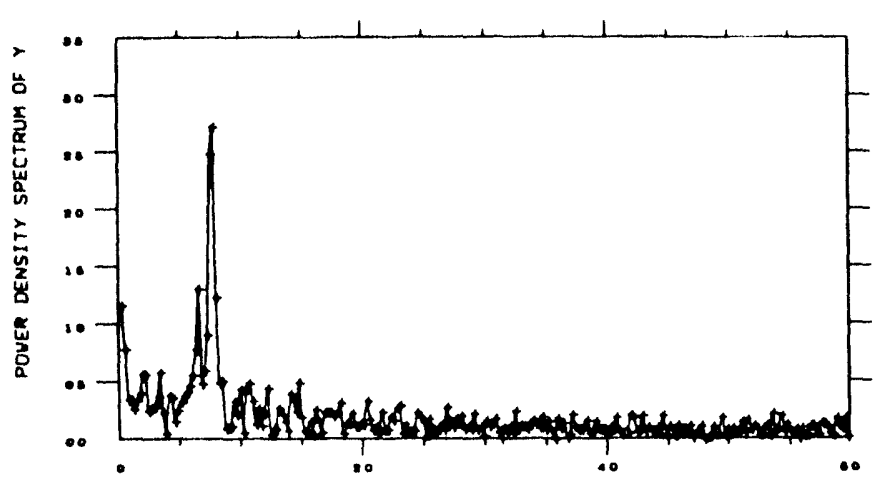

Frequency (Hz)

Figure 2 Frequency spectrum of the beam oscillation in the upper plot of Figure 1. Note the resonance at about $7 \mathrm{~Hz}$.

accelerating structures is schematically shown in Figure 3. The ends are rigidly attached to the floor and wall but the center is free to vibrate, modified somewhat by loose connections to the tunnel from RF power feeds, cooling water connections, quadrupole power connections, vacuum pumping lines, and diagnostic cables.

To measure the girders, access to the tunnel was made under near running condition with the water pumps, helium compressors, and cooling towers operating. The vibrations of the girders were measured using a light-weight ICPTM 308B02 accelerometer ${ }^{3}$ with a $1 \mathrm{v} / \mathrm{g}$ sensitivity and a frequency range of 1 to $3000 \mathrm{~Hz}$. The signals were analyzed using an Hewlett-Packard Lynamic Signal Analyzer ${ }^{4}$ HP3560A. A typical signal measurement versus time is shown in Figure 4 and the frequency spectrum of that measurement is shown in Figure 5. Many girders were measured and the data are summarized in Table 1. The girder amplitudes and frequencies change slightly depending on their location. This is due in part to the changing driving forces from the tunnel which, in turn, depend on the distance and orientation from the sources (heavy pumps, etc.) and from external connections (RF feeds, water connection,...). Also note that the lightly loaded girders have slightly higher frequencies, e.g. Girders 2-1, 3-1, 3-2, and 3-3.

The combined effects of these vibrating girders on the beam trajectory can be calculated. The vertical position $\Delta Y$ at a position monitor, say monitor LI03-321 as in Figure 1, is the sum of the contributions of the vibrations of all the quadrupoles upstream and the effects of the lattice transport.

$$
\Delta Y(t)=\Sigma_{\text {quads }} R_{12} Q \Delta y \sin (2 \pi f t) / B p
$$

where $R_{12}$ is the angle-to-position TRANSPORT element from the location of the vibrating quadrupole to the position monitor including energy changes. $Q$ is the integrated strength of the vibrating quadrupole, $\Delta y$ is the quadrupole vibration amplitude, $f$ is the vibration frequency, $t$ is time, and $B \rho$ is the beam's magnetic rigidity. A calculation was done using the data in Table 1 to predict the beam data in the upper plot in Figure 1. The result of the calculation is shown in Figure 6. The amplitude and variability of the predicted beam position resemble strongly those seen with the real data.

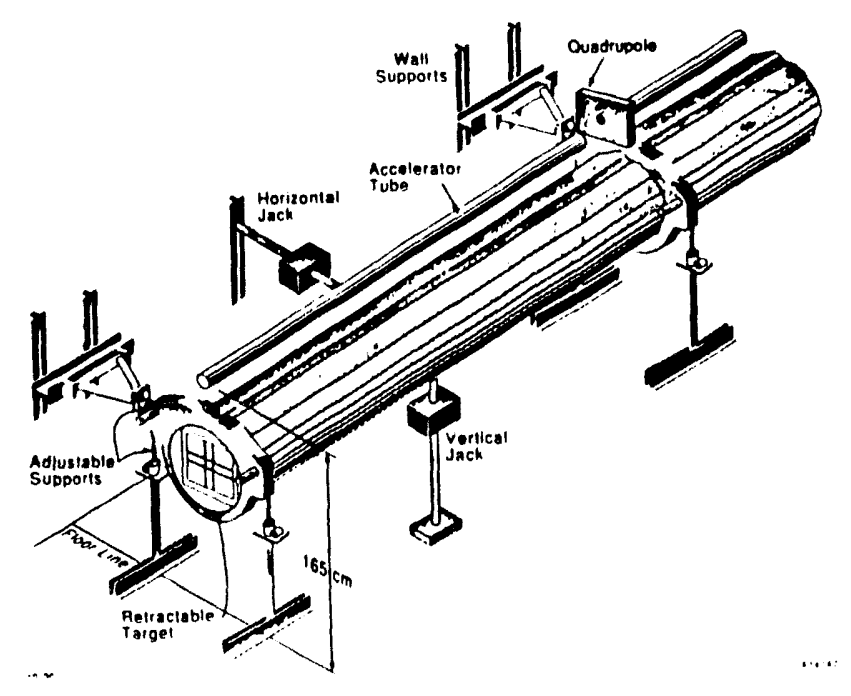

Figure 3 Schematic overview of the accelerator support girder.

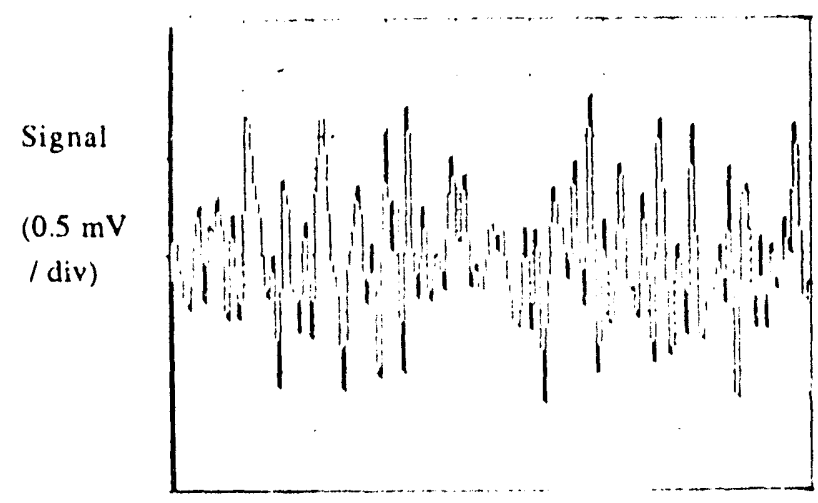

Time ( $2 \mathrm{sec} / \mathrm{div})$

Figure 4 Measured vertical vibration of Girder $2-4$ vs time.

\section{The Cure: Girder Struts}

The cure for these vibrations was to install horizontal and vertical mechanical struts (clamps) attached to the floor and wall near each quadrupole on the affected girders. A schematic view showing these struts at the girder center can be seen in Figure 3. After the strut installation the measured girder vibrations at $7 \mathrm{~Hz}$ were no longer visible as can be seen in Figure 7. However, vibrations appeared at higher frequencies 


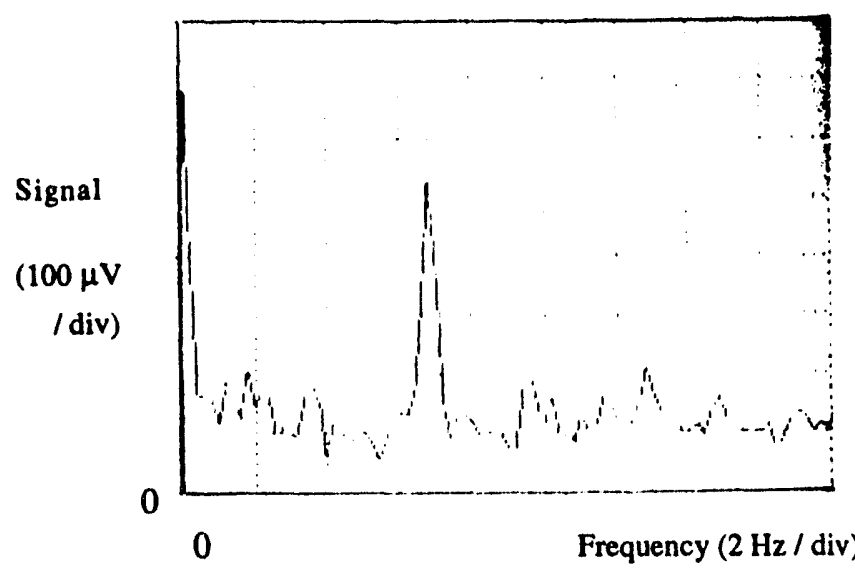

Figure 5 Vertical frequency spectrum of Girder 2-4 (Fig. 4).

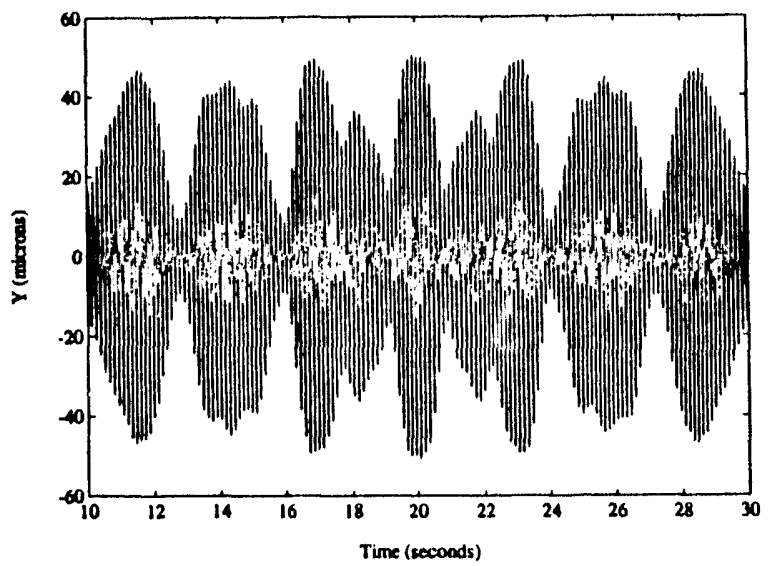

Figure 6 Predicted beam oscillation with time from the girder vibration data in Table 1 and the quadrupole lattice at the beam monitor in Fig. 1.

Table 1 Measured vibration frequencies and amplitudes of the centers of the first 11 girders ( $12 \mathrm{~m}$ each) of the linac using an accelerometer.

\begin{tabular}{|l|l|l|l|l|}
\hline $\begin{array}{l}\text { Girder } \\
\text { number }\end{array}$ & $\begin{array}{l}\text { Horizontal } \\
\text { Frequency } \\
(\mathrm{Hz})\end{array}$ & $\begin{array}{l}\text { Horizontal } \\
\text { amplitude } \\
(\mathrm{nm})\end{array}$ & $\begin{array}{l}\text { Vertical } \\
\text { frequency } \\
(\mathrm{Hz})\end{array}$ & $\begin{array}{l}\text { Vertical } \\
\text { amplitude } \\
(\mathrm{nm})\end{array}$ \\
\hline $2-1$ & 6.4 & $\ldots$ & 7.1 & $\ldots$ \\
\hline $2-2$ & 5.6 & 4000 & 6.4 & 1920 \\
\hline $2-3$ & 5.5 & $\ldots-$ & 6.8 & 3200 \\
\hline $2-4$ & 5.6 & 1400 & 6.45 & 2000 \\
\hline $2-5$ & 5.4 & 1400 & 6.75 & 4000 \\
\hline $2-6$ & 5.7 & 680 & 6.6 & 2520 \\
\hline $2-7$ & 5.4 & 1200 & 6.7 & 3200 \\
\hline $2-8$ & $\ldots$ & 1600 & 6.6 & 2040 \\
\hline $3-1$ & 7.2 & 2800 & 7.75 & 4800 \\
\hline $3-2$ & $\ldots$ & $\ldots$ & 7.4 & 5600 \\
\hline $3-3$ & $\ldots$ & $\ldots$ & 8.0 & 7600 \\
\hline
\end{tabular}

due to other modes of the structure and the installation orientation of the struts. Fortunately, the amplitudes of the vibrations at these higher frequencies are below the required tolerances. The consequences of the installation of the struts on the motion of the beam was immediate. The beam oscillations at $7 \mathrm{~Hz}$ were gone.

With the success of this linac effort, a search is now underway to look for smaller oscillations with signals at different frequencies coming from sources upstream of the linac.

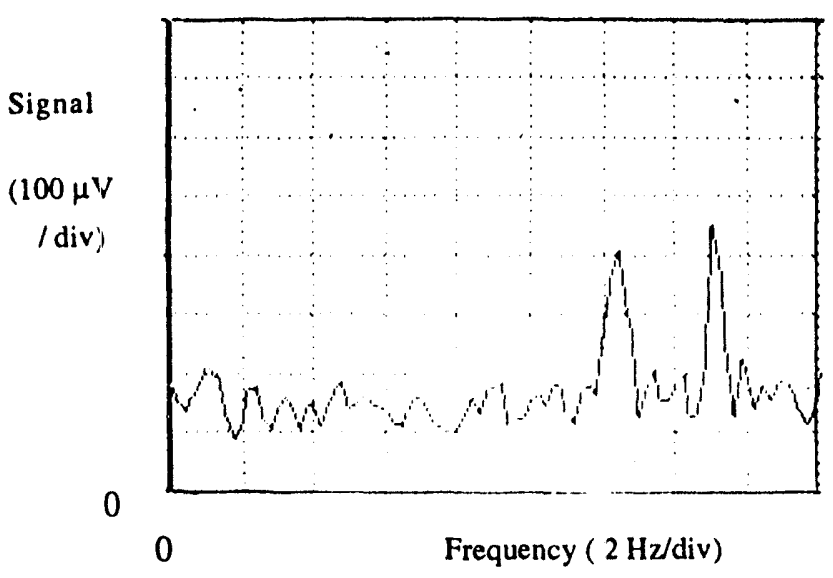

Figure 7 Measured vertical frequency spectrum of a girder with a center strut (clamp) installed. Note that higher frequencies appeared at $12-15 \mathrm{~Hz}$, about twice the old resonant frequency.

\section{Acknowledgments}

The authors wish to thank the SLC Operations Staff for helping with the beam measurements. R. Pennacchi, K. Burrows, and members of the Mechanical Fabrication Department installed the girder struts.

\section{References}

1) R. Stiening, How straight is the linac and how much does it vibrate?", SLAC Note CN-42, Stanford, January 1981, (unpublished).

2) K. McLagan, SLC Intergirder Quad Vibrations, SLAC Note CN-271, Stanford, June 1984, (unpublished).

3) Piezotronic, Inc., 3425 Walden Ave., Depew, NY 14043.

4) Hewlett-Packard, Page Mill Rd, Palo Alto, CA 94305 

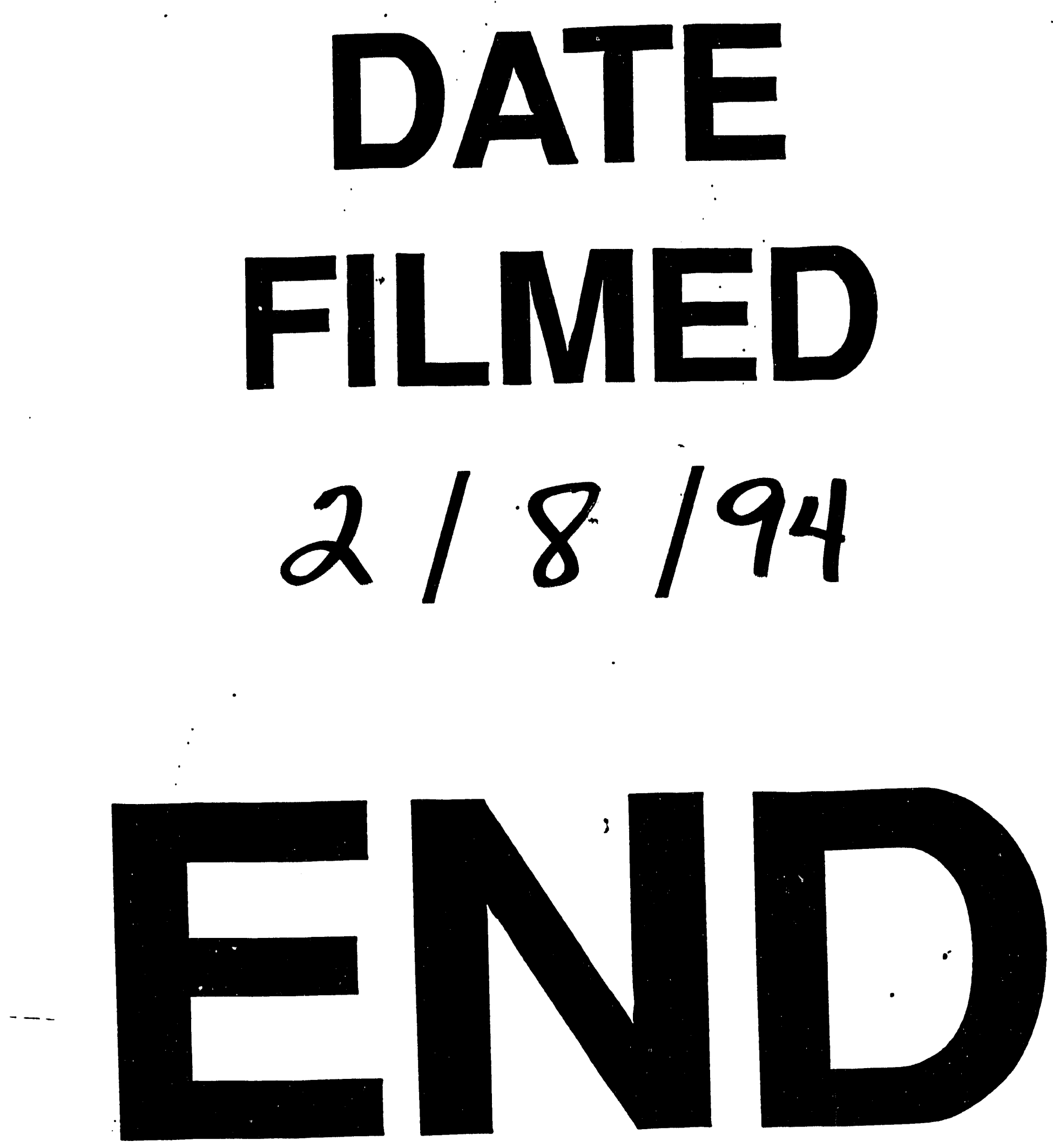
